\title{
Misuse of booster seats
}

\author{
S D Morris, K B Arbogast, D R Durbin, F K Winston
}

\begin{abstract}
Objective-To describe several aspects of booster seat use and misuse in a sample of children attending child safety seat clinics.

Methods-Booster seat practices were assessed at 76 child safety seat clinics held between April 1997 and January 1999 in Pennsylvania and southern New Jersey. At each assessment, a child passenger safety team evaluated the booster seat and identified modes of misuse.

Results-Altogether 227 booster seats were observed. Sixty eight per cent $(68 \%)$ of shield boosters and $20 \%$ of belt positioning boosters were misused. Thirty two per cent of the children using a shield booster weighed more than $40 \mathrm{lb}(18.1 \mathrm{~kg})$; $68 \%$ of children in shield boosters and $63 \%$ in belt positioning boosters weighed less than $40 \mathrm{lb}$.

Conclusions-This study identified a relatively high rate of booster seat misuse. Shield boosters were more likely to be misused than belt positioning booster seats. Significant numbers of children weighing more than $40 \mathrm{lb}$ were using possibly dangerous shield boosters. The majority of children in this study were less than $40 \mathrm{lb}$. In this weight range, a convertible child restraint system provides better protection than a booster seat. Booster seat use should only be initiated once the child has completely outgrown their convertible child restraint system.

(Injury Prevention 2000;6:281-284)
\end{abstract}

Keywords: shield booster; belt positioning booster; misuse; child safety seat clinic

The Children's

Hospital of

Philadelphia,

Philadelphia,

Pennsylvania

S D Morris

K B Arbogast

University of

Pennsylvania and The

Children's Hospital of

Philadelphia,

Philadelphia,

Pennsylvania

D R Durbin

F K Winston

Correspondence to: Shannon D Morris, The Children's Hospital of

Philadelphia, 34th and Civic

Center Boulevard, 3535

TraumaLink, 10th Floor

Philadelphia, PA 19104,

USA (MORRISS@

email.chop.edu)

Correct safety belt fit is important for ensuring the protection of school age children in motor vehicle crashes. ${ }^{1}$ A properly fitting safety belt is one in which the lap portion of the belt rides low over the child's hips and remains positioned over the iliac crests. The shoulder portion of the belt should rest on the shoulder and cross over the sternum without touching the child's neck. ${ }^{1}$ With correct fit, the force of a crash is spread over hard bony structures of the body. Vehicle seat belts, however, are designed for adult passengers, not children. Therefore, correct safety belt fit is usually not achieved until children are between 60 and $80 \mathrm{lb}(27.2$ and $36.3 \mathrm{~kg}$ ) and between 50 and 60 inches tall (127 and $152 \mathrm{~cm}$; that is approximately 8 years old). ${ }^{2}$ In motor vehicle crashes, children using ill fitting seat belts can suffer from serious abdominal and spinal cord injuries, termed "seat belt syndrome". ${ }^{4}$
Booster seats help prevent these injuries by providing protection for children who have outgrown their convertible child restraint system but are too small to properly fit into a vehicle seat belt. There are two types of booster seats: shield and belt positioning. Shield boosters have a plastic shield that rests over the child's abdomen and are designed for use in seating positions with lap belt only seat belt systems (fig 1). A belt positioning booster seat, designed for use with a lap/shoulder belt, is a platform that raises the child up so that the belt fits properly. It enables the lap portion of the belt to remain low over the hips, the shoulder portion to fall across the mid-portion of the shoulder, and the child to remain seated against the back of the seat. ${ }^{2}$ There are two styles of belt positioning booster seats: low back and high back (fig 2).

As with other child restraint systems, misuse likely reduces the safety benefits of booster seats. ${ }^{3}$ Previous reports have documented the extremely high misuse rates of child restraints, ${ }^{5-8}$ but little focus has been placed on the misuse of booster seats either nationally or internationally.

Internationally, booster seat use is widespread, a situation very different than that in the United States. For almost 20 years, low and high back belt positioning booster seats have existed in Europe, while shield booster use is minimal (D Burleigh, personal communication). In some countries, they are widely accepted and viewed as a logical next step after a child outgrows a convertible child restraint system (M Griffiths, personal communication). This acceptance of booster seats internationally may be due to the fact that they have been in existence for a long time and, in some

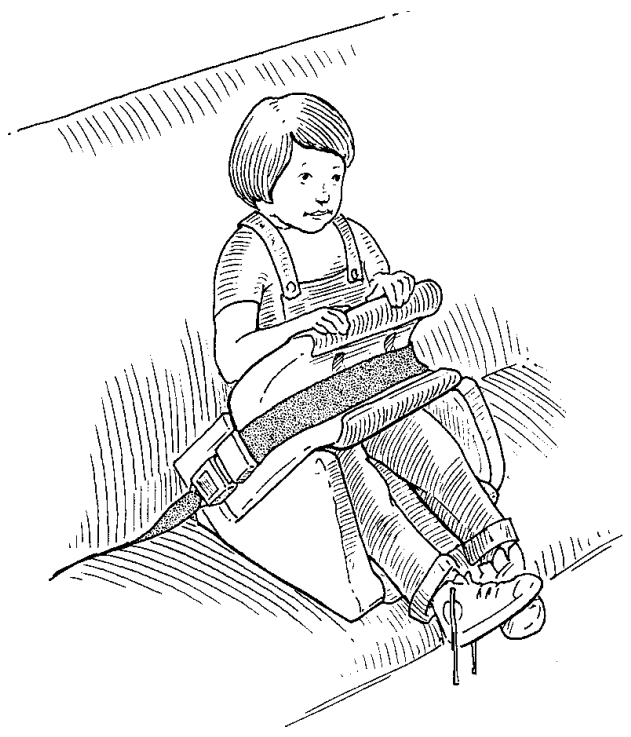

Figure 1 Shield booster seat. 
Low back

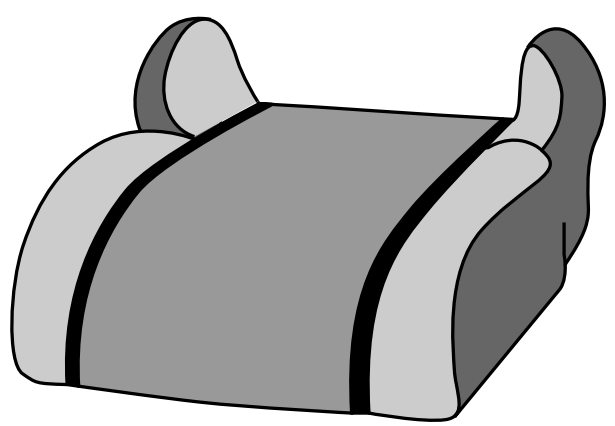

High back

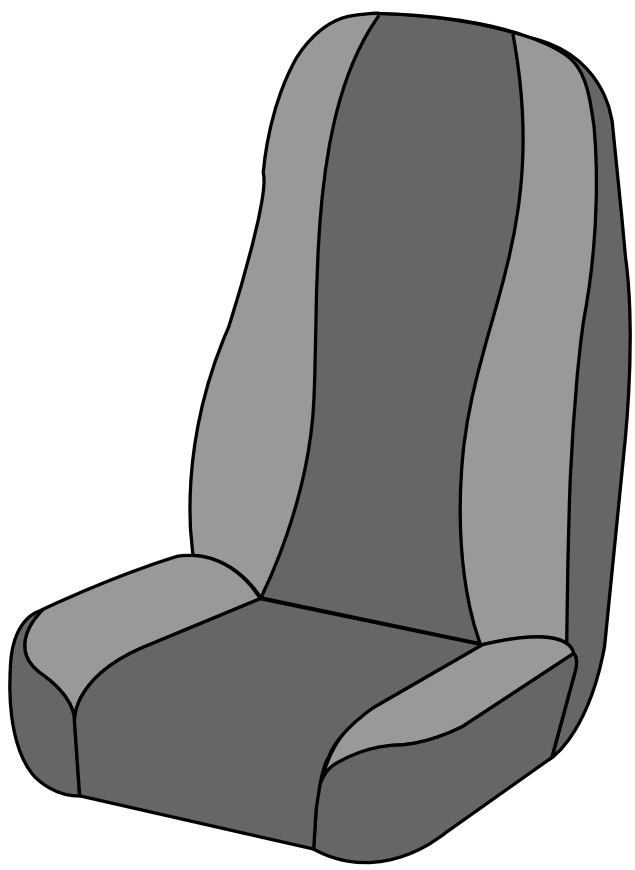

Figure 2 Belt positioning booster seat.

areas, are legally required. For example, in Germany, children up to 12 years of age and less than $1.5 \mathrm{~m}$ (57 inches) in height are required by law to use an appropriate restraint, which includes a belt positioning booster seat (D Burleigh, personal communication).

In the United States, however, booster seat use is extremely low. ${ }^{9}$ With current advocacy projects in effect in the United States, ${ }^{3}$ the popularity of these seats will likely increase. It is crucial that we assess the proportion of booster seat misuse early so that these errors can be proactively addressed.

The objective of this study was to describe several aspects of booster seat use and misuse in a sample of children attending child safety seat clinics. In particular, documentation of booster seat use practices was used to quantify their misuse and to identify the common misuse modes among each of the two seat types.

\section{Methods}

Characteristics of booster seat use were assessed at 76 child safety seat clinics held between April 1997 and January, 1999 in Pennsylvania and southern New Jersey. The clinics were held at a variety of locations such as automobile dealerships, shopping centers, hospitals, and parent group gatherings primarily in greater Pennsylvania metropolitan areas (Harrisburg, Pittsburgh, and Philadelphia). At these clinics, a team of trained child passenger safety advocates conducted a comprehensive on-site assessment of the booster seat with the child in place in the vehicle. The two advocates jointly evaluated the seat to establish whether or not a specific mode of misuse was present.

Four characteristics of booster seat use were assessed: booster seat type, the appropriateness of the booster seat for the child's age and weight, the fit of the child in the seat, and the fit of the booster seat in the vehicle. A standardized checklist, developed by the Pennsylvania Chapter of the American Academy of Pediatrics, was used to catalogue these characteristics. Up to seven possible misuses were evaluated for shield booster seats and up to four were noted for belt positioning boosters.

Descriptive statistics, including frequencies of categorical variables and mean (SD), median, and range for continuous variables, were calculated. The proportion of misuse in the study sample was calculated, as well as the proportion of specific modes of misuse. Differences in the proportion of misuse by booster seat type were determined using the $\chi^{2}$ test.

\section{Results}

A total of 227 booster seats were evaluated: $72 \%$ (164) were belt positioning boosters, $26 \%$ (59) were shield booster seats, and $2 \%$ (4) were of unknown type.

The mean (SD) age and weight of the children included in the study sample was 44 (13) months and 37 (7) $\mathrm{lb}(16.8$ (3.2) $\mathrm{kg}$ ), respectively. The weight distribution of the children included in the sample is shown in table 1 and specific subgroups should be noted. The majority of the children ( $68 \%$ of children in shield boosters and $63 \%$ of children in belt positioning boosters) were less than $40 \mathrm{lb}(18.1$ $\mathrm{kg}$ ). Of note, some children as small as $18 \mathrm{lb}$ $(8.2 \mathrm{~kg})$ were placed in booster seats.

Overall, $56 \%$ of the seats demonstrated at least one form of misuse. There was a significant difference in misuse by booster seat type: $68 \%$ of the shield boosters were misused,

Table 1 Per cent of booster seat restrained children by weight and seat type

\begin{tabular}{llc}
\hline Booster type & Weight $(\mathrm{lb})^{\star}$ & Children (\%) \\
\hline All boosters & $<30$ & 6 \\
& $30-40$ & 58 \\
Belt positioning booster & $>40$ & 36 \\
& $<30$ & 7 \\
Shield booster & $30-40$ & 56 \\
& $>40$ & 37 \\
& $<30$ & 5 \\
& $30-40$ & 63 \\
& $>40$ & 32
\end{tabular}

$\star 30 \mathrm{lb}=13.6 \mathrm{~kg} ; 40 \mathrm{lb}=18.1 \mathrm{~kg}$. 
Table 2 Misuse mode percentages for each booster seat type

\begin{tabular}{lll}
\hline Booster type & Misuse mode & Misuse rate (\%) \\
\hline Shield booster $(\mathrm{n}=59)$ & Locking clip used incorrectly or not used at all, when needed & 78 \\
& Booster seat not secured tightly with seat belt & 73 \\
& Shield not close to child's body & 21 \\
& Inappropriate seat belt system for booster seat & 9 \\
& Vehicle seat belt routed incorrectly & 8 \\
& Child inappropriate height/weight for booster seat & 2 \\
Beoster seat in a crash & 14 \\
& Shoulder belt incorrectly positioned & 6 \\
& Child inappropriate height/weight for booster seat & 6 \\
& Inappropriate vehicle seat belt system for booster seat & 4
\end{tabular}

compared with $20 \%$ of the belt positioning booster seats $(\mathrm{p}<0.001)$. The most common modes of misuse for shield boosters were: improperly using the locking clip when needed $(78 \%)$, not installing the seat tightly $(73 \%)$, and not fastening the shield close to the child's body $(21 \%)$. The most common mode of misuse for belt positioning boosters was incorrectly positioning the shoulder belt (14\%) (table 2).

Odds ratios were calculated for misuse based on seat type, weight, and age (table 3 ). Shield boosters were 8.7 times more likely to be misused than belt positioning boosters $(95 \%$ confidence interval 4.5 to $16.8, \mathrm{p}<0.0001)$. In addition, children weighing less than $40 \mathrm{lb}$ were 2.1 times more likely to be sitting in a misused booster seat than those children weighing greater than or equal to $40 \mathrm{lb}$ (95\% confidence interval 1.1 to $3.8, \mathrm{p}=0.02$ ). There was no difference in misuse for the two age groups tested $(<4$ years and $\geqslant 4$ years)

\section{Discussion}

This paper is the first to describe booster seat misuse patterns and reveal a relatively high rate of misuse. In particular, our results demonstrate that shield boosters were much more likely to be misused than belt positioning boosters. This difference can be attributed to the simplicity of belt positioning booster seats. These seats simply rest on the vehicle seat while the lap/shoulder belt is used in its regular manner. Shield boosters, in contrast, must be installed tightly using the vehicle seat belt. Parents may experience compatibility problems between the vehicle seat, vehicle seat belt and the shield booster, similar to infant and convertible child restraint installation, that lead to the inability to install the seat tightly. In Europe and Australia, shield boosters are not widely used thus this incompatibility issue is

Table 3 Odds ratios for misuse by seat type, weight, and age

\begin{tabular}{|c|c|c|c|}
\hline & $\begin{array}{l}\text { \# of seats } \\
\text { misused }\end{array}$ & $\begin{array}{l}\text { \# of seats not } \\
\text { misused }\end{array}$ & $\begin{array}{l}\text { Odds ratio } \\
\text { (95\% confidence interval) }\end{array}$ \\
\hline \multicolumn{4}{|l|}{ Booster type } \\
\hline Shield booster $(n=59)$ & 40 & 19 & $8.7(4.5$ to 16.8$)$ \\
\hline Belt positioning booster $(n=164)$ & 32 & 132 & $\mathrm{p}<0.0001$ \\
\hline \multicolumn{4}{|l|}{ Weight $(l b)^{\star}$} \\
\hline$<40(\mathrm{n}=136)$ & 53 & 83 & $2.05(1.1$ to 3.8$)$ \\
\hline$\geqslant 40(\mathrm{n}=76)$ & 18 & 58 & $\mathrm{p}=0.02$ \\
\hline \multicolumn{4}{|l|}{ Age (years) } \\
\hline$<4(\mathrm{n}=114)$ & 40 & 74 & $1.2(0.7$ to 2.1$)$ \\
\hline$\geqslant 4(\mathrm{n}=100)$ & 31 & 69 & $\mathrm{p}=0.5$ \\
\hline
\end{tabular}

$\star 40 \mathrm{lb}=18.1 \mathrm{~kg}$. not a common problem (D Burleigh, $M$ Griffiths, personal communication).

Shield boosters have additional safety risks. They have been implicated in serious injuries to children who weigh more than $40 \mathrm{lb}^{10}$ The lack of upper body restraint in shield booster seats allows for a greater amount of head excursion and this may lead to serious head or brain injuries. In addition, evidence exists that older, taller children with a higher center of gravity may be ejected from these seats. ${ }^{10}$ In our study, almost one third of children using a shield booster weighed more than $40 \mathrm{lb}$. In contrast to shield boosters, belt positioning boosters restrain both the child's lower and upper body by using the vehicle's lap and shoulder belt, thereby reducing the risk of significant forward excursion. As a result of these safety risks, shield boosters are not recommended for children over $40 \mathrm{lb}^{{ }^{12}{ }^{10}}$

However, parents in the United States who own a older model vehicle with lap belt only seat belts present in the rear seating positions are faced with a difficult decision. Belt positioning booster seats cannot be used with lap belt only seat belts and current best practice would not recommend the child be restrained in a lap only belt. In this situation, safety advocates would recommend that the parents have their vehicle retrofitted with lap/shoulder belts in the rear seat so that a belt positioning booster could be utilized. Often, parents do not see this as a reasonable option. Internationally, this problem rarely exists (D Burleigh, M Griffiths, personal communication). Lap/shoulder belts have been fitted to the outboard rear seating positions in European vehicles for over 20 years (D Burleigh, personal communication) and have existed in Australian vehicles in all three rear seating positions (two outboard and the center seat) for over 30 years (M Griffiths, personal communication).

Over one third of the children in this study weighed greater than $40 \mathrm{lb}$ and were restrained in a shield booster. Many of these children were riding in a vehicle equipped with a lap belt only in the child's seating position. In order to restrain the child in a child restraint, the only option for these parents was to restrain the child in a shield booster.

In this study, over half of the children using booster seats weighed less than $40 \mathrm{lb}$. However, better restraint alternatives exist for children in this weight range, such as a convertible child restraint system. ${ }^{1511}$ Most convertible child 
restraint systems are certified for children up to $40 \mathrm{lb}$, and, as a result, children weighing $40 \mathrm{lb}$ or less should remain in this restraint system until they reach the maximum height/weight limits. When used correctly, a convertible child restraint system provides biomechanical benefits by spreading the crash forces over the shoulders and hips. Depending on the harness type of the seat, a convertible child restraint system restrains the child in at least three body locations (above each shoulder and between the legs), and in up to five locations (above each shoulder, one each side of the hips, and between the legs). ${ }^{12}$ In addition, the increased protection restricts children from getting out of the seat.

Currently, at child safety seat clinics, if parents are following manufacturer recommendations with use of the booster but are not following best practice (using shield boosters for children over $40 \mathrm{lb}$ or using a booster instead of a child restraint system for children under $40 \mathrm{lb}$ ), education is provided and an alternative seat is suggested. In most cases, booster seats are available at the child safety seat clinics, free of cost or for a small donation, for children who weigh greater than $40 \mathrm{lb}$ and are not currently restrained in a booster seat or for those children restrained in an unsafe booster seat.

This study was conducted on a self selected sample of parents voluntarily attending a child safety seat clinic, and thus, may not be representative of all parents using booster seats. However, the results presented, based on a sample of motivated parents, underscore the magnitude of the misuse problem.

Misuse was less common with belt positioning booster seats than shield boosters. The additional concern from previous research regarding suboptimal upper body restraint in shield boosters ${ }^{10}$ suggests that a belt positioning booster is the booster of choice. Although belt positioning boosters may be more costly than shield boosters, inexpensive models do exist. It is crucial, however, that booster seat use is initiated once the child has completely outgrown the convertible child restraint system in order to maximize safety.

\section{Implications for prevention}

Findings from this study have implications for child restraint manufacturers and for the health education community. Manufacturers need to devise more user friendly instruction manuals to parents and care givers so they may continue to reduce the most common booster seat misuses. Furthermore, the instruction manuals should be updated to match current best practice guidelines. In parallel, health educators must instruct parents and caregivers about the dangers of premature graduation from convertible child seats to boosters, and the risks associated with shield boosters for children over 40 lb. Best practice, the use of belt positioning boosters for children over $40 \mathrm{lb}$, should be emphasized.

The authors would like to acknowledge the Pennsylvania Chapter of the American Academy of Pediatrics' Traffic Injury Prevention Project, a program funded by the Pennsylvania Department of Transportation, especially Lorrie Walker, for their assistance in organizing the collection of the checklist forms, the many child passenger safety advocates in Pennsylvania and New Jersey for conducting the checkpoints and the State Farm Insurance Companies for their financial assistance.

In addition, the authors would like to acknowledge Michael Griffiths of Road Safety Solutions and David Burleigh of Britax Childcare Safety Systems for their contribution on booster seat use internationally.

1 Winston FK, Durbin DR. BUCKLE UP! is not enough: enhancing the protection of the restrained child. $7 A M A$ 1999;281:2070-2.

2 Klinich K, Pritz H. Study of older child restraint/booster seat fit and NASS injury analysis. East Liberty, $\mathrm{OH}$ : National Highway Traffic Safety Administration, Vehicle Research and Test Center, 1994.

3 Blue Ribbon Panel II. Protecting the older child. Washington, DC: Blue Ribbon Panel II, 1999.

4 Lane J. The seat belt syndrome in children. Accid Anal Prev 1994;26:813-20.

5 Decina LE, Knoebel KY. Child safety seat misuse patterns in four states. Accid Anal Prev 1997;29:125-32.

6 Gotschall C, Eichelberger M, Morrissey J, et al. Injury patterns associated with child restraint misuse. Second child occupant protection symposium. Orlando, FL: Society of Automotive Engineers Inc, 1997.

7 Bull MJ, Stroup KB, Gerhart S. Misuse of car safety seats. Pediatrics 1988;81:98-101.

8 Campbell H, Macdonald S, Richardson P. High levels of incorrect use of car seat belts and child restraints in Fife-an important and under-recognised road safety issue. Inj Prev 1997;3:17-22.

9 Winston F, Durbin D, Kallan M, et al. The danger of premature graduation to seat belts for young children. Pediatrics (in press).

10 Whitman G, Brown K, Cantor A, et al. Booster-with-shield child restraint case studies. Second child occupant protection symposium. Orlando, FL: Society of Automotive Engineers Inc, 1997.

11 Committee on Injury and Poison Prevention. Selecting and using the most appropriate car safety seats for growing children: guidelines for counseling parents. Pediatrics 1996; 97:761-2.

12 Weber K. Child passenger protection. In: Nahum A, Melvin J, eds. Accidental injury: biomechanics and prevention. New York: Springer-Verlag, 1993. 